\title{
Aerosols optical depth and Ångström exponent over different regions in Garhwal Himalaya, India
}

\author{
Amar Deep · Chhavi Pant Pandey $\cdot$ Hemwati Nandan $\cdot$ Narendra Singh \\ Garima Yadav $\cdot$ P. C. Joshi $\cdot$ K. D. Purohit $\cdot$ S. C. Bhatt
}

Received: 2 August 2020 / Accepted: 4 April 2021 / Published online: 4 May 2021

(C) The Author(s), under exclusive licence to Springer Nature Switzerland AG 2021

\begin{abstract}
Aerosol optical depth (AOD) and Ångström exponent (AE) are observed to be important parameters in understanding the status of ambient aerosol concentration over a particular location and depend not only upon the local but also on the large-scale dynamics of the atmosphere. The present article analyses the AOD and AE parameters retrieved with Moderate Resolution Imaging Spectrometer (MODIS) and Multi-angle Imaging Spectro-Radiometer (MISR) instruments onboard satellites, for the upper (Chamoli) and foothill (Dehradun) regions of Garhwal Himalaya in Uttarakhand, India, from 2006 to 2015. Aerosol properties are investigated at monthly, seasonal, and annual scales. The monthly mean values of
\end{abstract}

A. Deep · G. Yadav · K. D. Purohit · S. C. Bhatt

Department of Physics, H N B University, Garhwal (A

Central University), 246174 Srinagar, Uttarakhand, India

C. P. Pandey ( $\bowtie)$

Wadia Institute of Himalaya Geology, 33 GMS Road,

Dehradun, 248001 Uttarakhand, India

e-mail: chhavi@wihg.res.in

H. Nandan · P. C. Joshi

Department of Physics and, Dept. of Environmental

Sciences, Gurukula Kangri (Deemed to be University),

Haridwar, 249404 Uttarakhand, India

\section{N. Singh}

Aryabhatta Research Institute of Observational Sciences,

Manora Peak, Nainital, 263001 Uttarakhand, India
MODIS-derived AOD and AE were observed to be $0.18( \pm 0.14)$ and $1.05( \pm 0.43)$ respectively over the Dehradun region. The seasonal maximums in AOD with MODIS and MISR were observed as $0.23 \pm 0.06$ and $0.29 \pm 0.07$ respectively in the pre-monsoon season, and the minimum values $(0.099 \pm 0.02)$ were observed in the post-monsoon season, over the Dehradun region. In contrast, in the Chamoli region, the maximum AOD (MODIS) was $0.21 \pm 0.06$ observed in the monsoon season and the minimum was $0.036 \pm 0.007$ in the post-monsoon season. Over a decade, the AE for Chamoli and Dehradun was found to vary from 0.07 to 0.17 and from 0.14 to 0.20 respectively. The median AE for Chamoli and Dehradun was found to be 1.49 and 1.47 respectively, marking the dominance of fine mode particles of anthropogenic origin. Observations show the presence of dust and polluted dust resulting from the longrange transport from the west. The comparison of AOD values from the two sensors shows a significant correlation (0.73) with slightly higher values from MISR over the year. The results obtained are important in understanding the climatic implications due to the atmospheric aerosols over the abovementioned Himalayan region of Uttarakhand, India.

Keywords AOD $\cdot \mathrm{AE} \cdot \mathrm{CALIPSO} \cdot \mathrm{MODIS}$ and MISR 


\section{Introduction}

All the solid particles and liquid droplets suspended in the ambient air are collectively known as atmospheric aerosols (Lippmann, 2000). Our environment is significantly affected by the scattering and absorptive characteristics of atmospheric aerosols (Lyamani et al., 2008; Srivastava et al., 2018). In particular, the tropospheric aerosols are very prevalent types, especially, with regional new particle formation of sub-micron range (i.e. secondary aerosols), which are produced through gas-to-particle conversion processes (Huang et al., 2020). This phenomenon leads to a lower rate of surface evaporation and increasing atmospheric stability. The optical and chemical properties of the abovementioned aerosols have a direct effect on radiative forcing, cloud formation, rainfall, visibility, and weather/climate variability in diverse context (IPCC, 2001; Filonchyk et al., 2019b). The indirect effects of aerosols depend on the type of aerosols, their size and vertical distribution, and meteorological conditions. Both the first and second indirect effects relieve the pressure of global warming by cooling the atmosphere (Myhre et al., 2006). Through the absorption of solar and infrared radiations, aerosols lead to the heating of the atmosphere while certain types of aerosol species may also have the potential to cool the Earth's surface (Kaufman et al., 2002). This counteractive impact of aerosols on the ambient air in our environment increases the uncertainty in quantifying their role in the climate variability of a particular region. The high concentration of aerosol particles in the environment (indoor as well as outdoor) leads to decreasing visibility in the atmosphere (Yang et al., 2016), and it also mediates various adverse health effects (Cohen et al., 2017; Mulenga \& Siziya, 2019) and is observed during the COVID-19 pandemic (Anchordoqui et al., 2020) as well. Their impact on precipitation products, climate change, and snowmelt runoff (Javadinejad et al., 2020; Thanh, 2019) in particular in the Himalayan region needs careful monitoring. Based on such standpoints, ambient particulate matter has been the focus of public concern because of its potential risks for several diseases, such as lung cancer, respiratory infections, and cardiovascular diseases (Brunekreef \& Holgate., 2002; Dominici et al., 2006; Gakidou et al., 2017).
A number of investigations on aerosols along with their overall impact on environmental quality and local climate have been noticed during the last two decades (Hansen et al., 1988; Dammann et al., 2002; Kanakidou et al., 2005; Von Schneidemesser et al., 2015; Vanos et al., 2015; Dhaka et al., 2020). The estimation of aerosol optical depth (AOD) at various suitable wavelengths is one of the essential, easier, and suitable parameters for the characterization of aerosols. AOD in fact has a direct relation with processes such as scattering and absorption of radiation in the atmosphere (Ranjan et al., 2007) and is being frequently used for analysing the atmospheric processes as well as for understanding the climate variability of different regions (Kaufman et al., 2002; Toledano et al., 2007; Sharma et al., 2012).

Further, the Angström exponent (AE) is also used as an important indicator of the foremost aerosol size (Eck et al., 1999; Cachorro et al., 2000; Schuster et al., 2006) because the spectral shape of the extinction is related to the particle size. In order to see the effect of AE, Kaskaoutis et al. (2007) studied the climatology of aerosol on the basis of AE over some AERONET sites. The effects of aerosol components (i.e. AOD and AE) using 13 years of data during 2001-2013 (Habib et al., 2019) were observed using the Aerosol Robotic Network (AERONET), Moderate Resolution Imaging Spectroradiometer (MODIS), and Multi-angle Imaging Spectroradiometer (MISR) over regions of the Asian desert. Further, according to Chen et al. (2020), the background aerosols (mainly continent aerosol) dominate with a combined occurrence ratio of over $70 \%$ and they have slight variations on the seasonal scale with the dominant aerosols showing strong seasonal variations. Nonetheless, with the significance of the climatic effect of aerosols and the importance of aerosols in cloud formation, many investigations have been performed by using the data of aerosol parameters (i.e. AOD and AE data) observed using the MODIS sensor with the onboard Terra and Aqua satellites (Kumar et al., 2014; Adesina et al., 2016; Hu et al., 2018; Boiyo et al., 2018).

In India, some studies of aerosols have also been conducted under the Indian Space Research Organi- 
zation: Geosphere-Biosphere Programme (ISROGBP). Eck et al. (1999) have estimated that the spectral dependence of AOD is important in adequately modelling the effects of aerosols on the radiation budget of the Earth's atmosphere system. Studies on AOD and transport of pollution have also been performed in the Indo-Gangetic Basin (IGB) (Dey \& Di Girolamo, 2010; Srivastava et al., 2012; Tiwari \& Singh, 2013). However, Sharma et al. (2012) have made some useful investigations on atmospheric aerosol ions with AOD at a higher altitude area in Kullu in the state of Himachal Pradesh, India. The IGP is an important region from various points of view such as economic activities and industrial development and thus depicts a higher level of anthropogenic emissions. Ground-based and space-borne observations have also been made and used for the studies in this region by (Solanki \& Singh, 2014). Observations on the vertical profile of aerosol and their transport at high altitude regions have also been made by Solanki et al. (2013), Kumar et al. (2018a, b); however, more intensive measurements are still needed over the Himalayas which is nearly a data-void region. The Indian Himalaya is topographically very fragile and ecologically very delicate, and further due to the variety of the ecosystem, surface conditions and aerosol properties, in situ observations of aerosols in this part of the Himalayas are therefore very important (Guleria et al., 2011, 2012). Our study mainly focuses on the aerosol variability at various scales, utilizing AOD and $\mathrm{AE}$ over a higher-altitude region i.e. Chamoli district, and a foothill Himalayan site i.e. Dehradun district of the state of Uttarakhand, India. The present article is organized as follows: the site description, data analysis and research methodology are presented in detail in "Site description, data analysis and methodology". The results are discussed in "Results and discussion", followed by summary and conclusions at the end.

\section{Site description, data analysis, and methodology}

For the present study, two sites located at different altitudes viz. Chamoli and Dehradun were selected in Garhwal Himalaya of Uttarakhand, India (Fig. 1). Area-wise, Chamoli (longitude
$79.60-79.63 \mathrm{E}$ and latitude $30.84-30.87 \mathrm{~N}$ ) is the second largest hill district of the Uttarakhand state of India and it is situated at an average altitude of 1400 amsl, whereas Dehradun (longitude 78.03-78.09 E and latitude 30.57-30.62 N) is the most populated district in Uttarakhand, which is situated in the south-western part of Uttarakhand state at an average altitude of $450 \mathrm{~m}$ amsl. Dehradun, which is the capital of the state of Uttarakhand, extends nearly $20 \mathrm{~km}$ in average width, and $80 \mathrm{~km}$ in length in the Shivalik range of Himalaya. During the last few decades, urbanization, industrialization, and vehicular emission in the Dehradun district have significantly increased the various anthropogenic activities resulting in increased pollution levels.

In the present paper, analysis of $\mathrm{AOD}$ and $\mathrm{AE}$ data collected from MODIS and MISR satellites from the abovementioned sites has been analysed. The Cloud-Aerosol Lidar and Infrared Pathfinder Satellite Observations (CALIPSO) data images have also been used in the present study to find out the dust episodes in the Western part and different regions of India.

Moderate resolution imaging spectroradiometer

The Moderate Resolution Imaging Spectroradiometer (MODIS) is a spaceborne sensor onboard the Terra satellite (launched in December 1999) and Aqua satellite (launched in May 2002). Both of these satellites scan the entire surface of the Earth, every 1 to 2 days and acquire data in 36 spectral bands or groups of a different wavelengths (Levy et al., 2007; Remer et al., 2005; Savtchenko et al., 2004; Yu et al., 2004). Two separate algorithms, i.e. Deep-Blue algorithm and Dark-Target algorithm (Mhawish et al., 2017), are utilized to retrieve the AOD (MODIS) data products.

In the present case, AOD data acquired using the MODIS sensor was obtained on daily and monthly basis from MOD08_D3_6 Level 3 (Terra platform) and MYD08_D3_6 (Aqua platform). The product of the AOD land data of MODIS utilizes Deep-Blue algorithm (corrected at $0.55 \mu \mathrm{m}$ ) which is available at $1^{\circ} \times 1^{\circ}$ spatial resolution. 

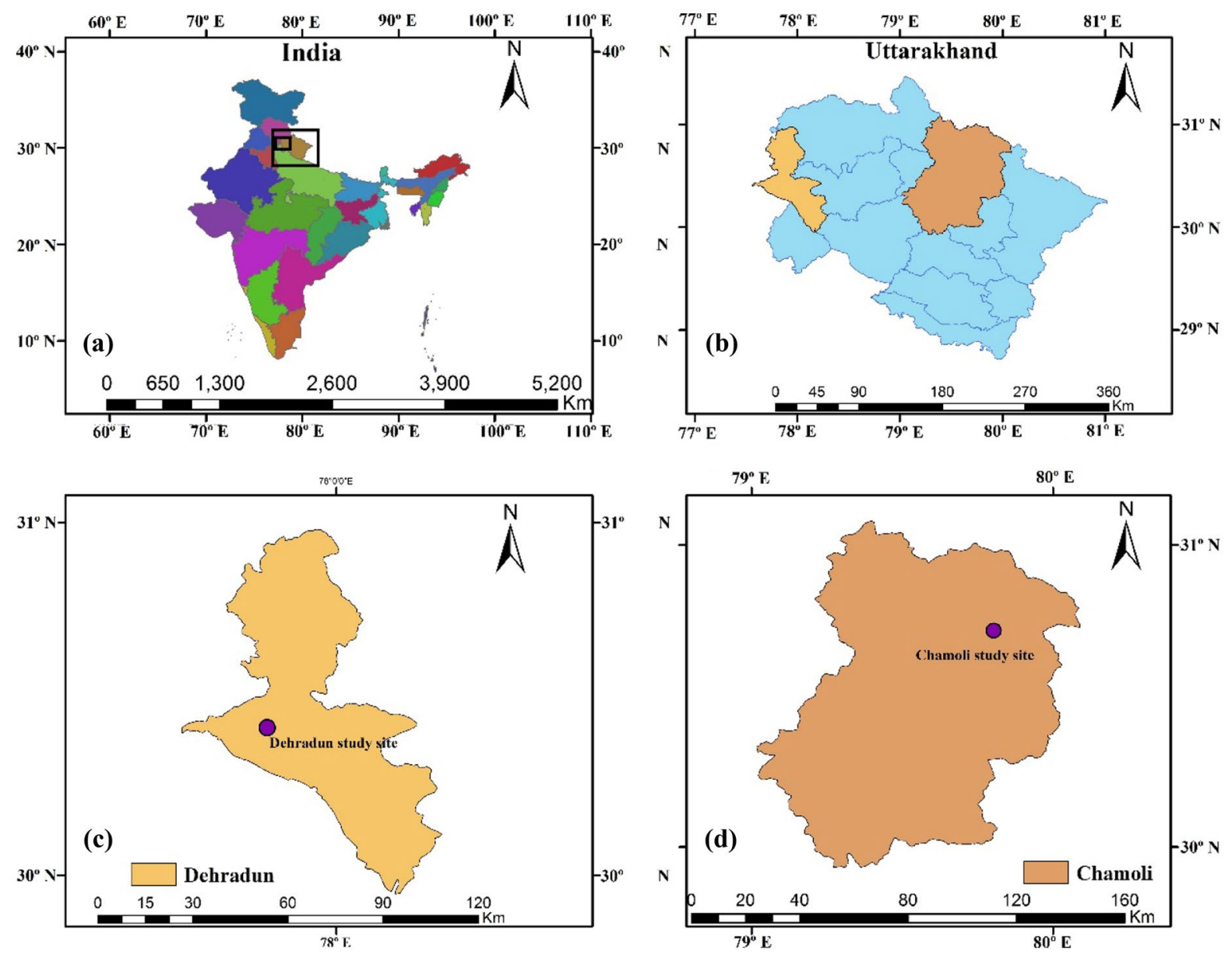

Fig. 1 a Location of study site in the map of India. b A geographically distinct region (districts) in the map of Uttarakhand. c Map of the Dehradun district indicating district headquarter. $\mathbf{d}$ Map of the Chamoli district indicating the district headquarter

Multi-angle Imaging Spectro-radiometer

The Multi-angle Imaging Spectro-Radiometer (MISR) (launched in October 1999) provides various atmospheric parameters on an hourly, daily, monthly and seasonal basis on both regional and global scales. The data of AOD from MISR was obtained with product MIL3DAE_4 for selected sites and has the resolution $0.5^{\circ} \times 0.5^{\circ}$ at $555 \mathrm{~nm}$. It is worth mentioning that MISR data is capable of distinguishing among different types of clouds, aerosols and surfaces. The AOD data to be used is calculated with the well-known Lambert-Beer law (Guleria et al., 2011).

\section{HYSPLIT air mass trajectory}

The Hybrid Single Particle Lagrangian Integrated Trajectory (HYSPLIT) model, developed by NOAA's Air Resources Laboratory, is applied in the present study. HYSPLIT computation methodology is a hybrid between a Lagrangian and Eulerian approach as described in detail by Stein et al. (2015). One of the common applications of the HYSPLIT model is to simulate back air-mass trajectory to determine the origin of air masses and establish source-receptor relationships is used in present study. 
Cloud-Aerosol Lidar and Infrared Pathfinder Satellite Observations

CALIPSO is a joint mission between the Space Agency NASA, USA, and the Centre National d'Etudes Spatiales (CNES), France. It is a part of A-Train constellation of satellites and is in operation since April 2006. The CALIPSO satellite is capable of observing the aerosols over the bright surface and beneath the thin clouds in clear sky conditions (Huang et al., 2008). With the help of depolarization techniques, CALIPSO can easily distinguish among the dust and all other types of aerosols (Liu et al., 2008). It also provides us the useful information about sources of aerosols generating from all over the globe. The influence of a long-range transportation from different sources of atmospheric aerosols to the study sites is also identified by air trajectories in conjunction with the CALIPSO data. The flowchart of overall research methodology is shown in Fig. 2.

\section{Results and discussions}

The statistical analysis of the data on AOD and $\mathrm{AE}$ has been carried out. The features of monthly,

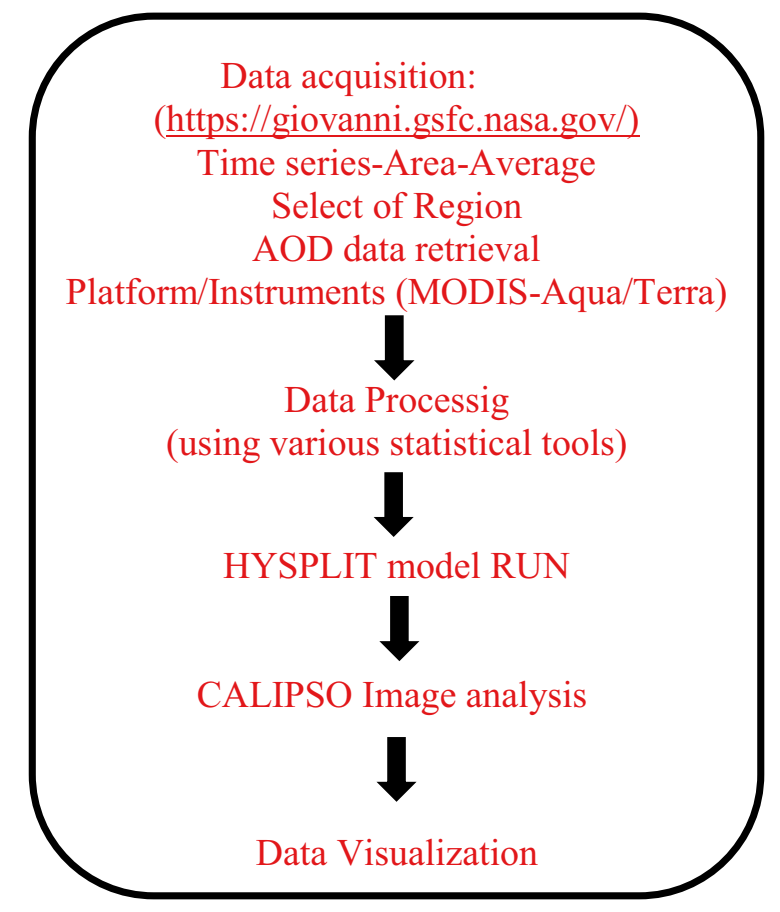

Fig. 2 Summary of the overall research methodology seasonal and annual variability of the AOD recorded over the study regions, during the period of study, are presented in the subsequent sections.

Monthly variability

Figures 3 and 4 show data on the monthly mean AOD and $\mathrm{AE}$ along with standard deviation recorded from selected sites. From Fig. 3a, for the Chamoli region, it is clear that the maximum monthly mean of AOD (MODIS) was observed as $0.314 \pm 0.164$ in the month of July and minimum AOD was observed as $0.025 \pm 0.006$ in the month of December, while for Dehradun region, the maximum AOD was observed in the month of May $(0.32 \pm 0.11)$ and minimum in the month of December $(0.06 \pm 0.004)$. Figure $3 b$ gives the comparison of AOD retrieved with MODIS and MISR over two sites, which indicates that the highest monthly AOD $(0.33 \pm 0.083$ by MODIS and $0.39 \pm 0.12$ by MISR) was recorded for the month of May and lowest monthly AOD $(0.07 \pm 0.018$ by MODIS and $0.13 \pm 0.06$ by MISR) for the month of December. The AOD measurements by the two sensors are closer during April, May and June, basically during summer months when pollution is well mixed within the boundary layer, whereas the other months are showing a larger variability with higher MISR AODs over the year.

Figure 4 shows the monthly mean variations in the observed data of $\mathrm{AE}$ with the standard deviation. In Dehradun district, the highest and lowest average monthly values of AE (MODIS) were observed as $1.56 \pm 0.18$ and $1.18 \pm 0.08$ in the months of July and May respectively. However, in the Chamoli district, corresponding values of the same were observed as $1.501 \pm 0.035$ and $1.32 \pm 0.28$ in the month of April and August respectively. The Angstrom exponent is basically a quantitative indicator and inversely proportional to the size of the aerosol particles. Mean $\mathrm{AE}$ is found to be more than 1 in most of the months which indicates primarily the presence of the fine mode particles over Dehradun and Chamoli regions during the year. However, during the spring (March-May) months, the Dehradun region is found to show the presence of larger size particles as $\mathrm{AE}$ values are approaching towards 1.0 to 1.2 . On the other hand, the Chamoli region is showing large variations in the monsoon months but mostly dominated by fine mode particles. 

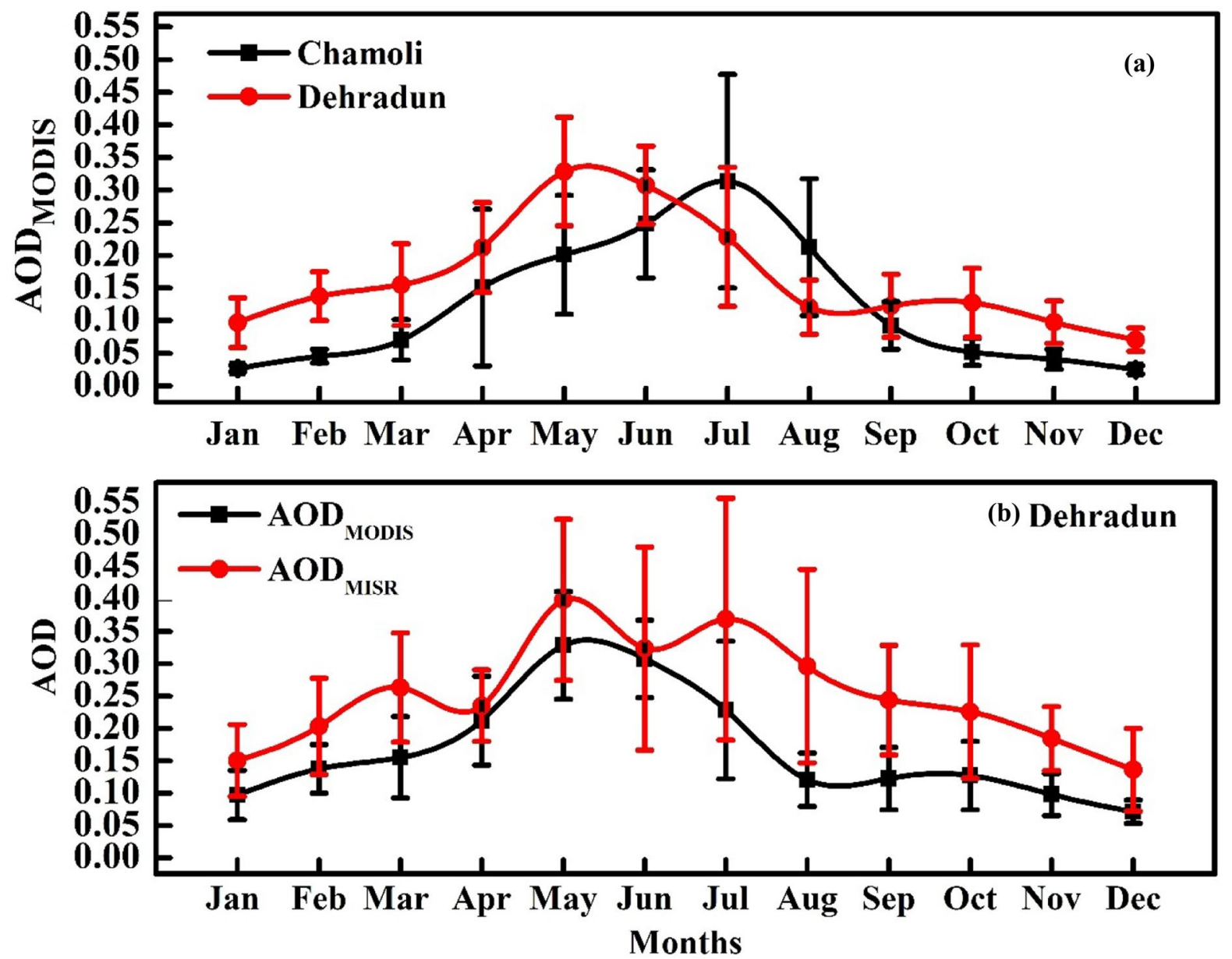

Fig. 3 a Average monthly variation of AOD (MODIS) recorded for both the study sites. b AOD (MODIS \& MISR) for the Dehradun district

\section{Seasonal and annual variability}

In this study, the seasons have been categorized as per the classification of the India Meteorological Department (IMD) i.e. winter (December-February), pre-monsoon (March-May), monsoon (June-September) and postmonsoon (October-November). The seasonal variations of AOD and AE are presented in Fig. 5. The maximum seasonal mean values of AOD (MODIS) over the Dehradun region were observed to be $0.23 \pm 0.06$ during the pre-monsoon season and for Chamoli region the maximum AOD $(0.21 \pm 0.06)$ was observed in the monsoon season. The lowest seasonal mean $0.036 \pm 0.007$ for Chamoli was observed in winter and that for Dehradun was in post-monsoon as $0.099 \pm 0.02$. The effect of monsoonal moist air and rain is not found to be that dominant during the season, but the post-monsoon season is eventually showing the lower AOD values for both regions. The largest part of the Chamoli region are the high-altitude Himalayas and relatively a pristine environment; contrary to it, the region is shown to have a higher value of AOD during the pre- monsoon and monsoon seasons. This is suggested to have resulted from the vehicular emissions and extensive use of transportation means, as summer and monsoon months are the pilgrimage seasons for Char Dham Yatra. This Yatra is basically a tradition of visiting temples in the Himalayas. In the process, millions of people from across the country and all over the world visit the Himalayan region, particularly, Chamoli district of the state. 
Fig. 4 Monthly variation of $\mathrm{AE}$ at the Dehradun and Chamoli regions in Uttarakhand, India

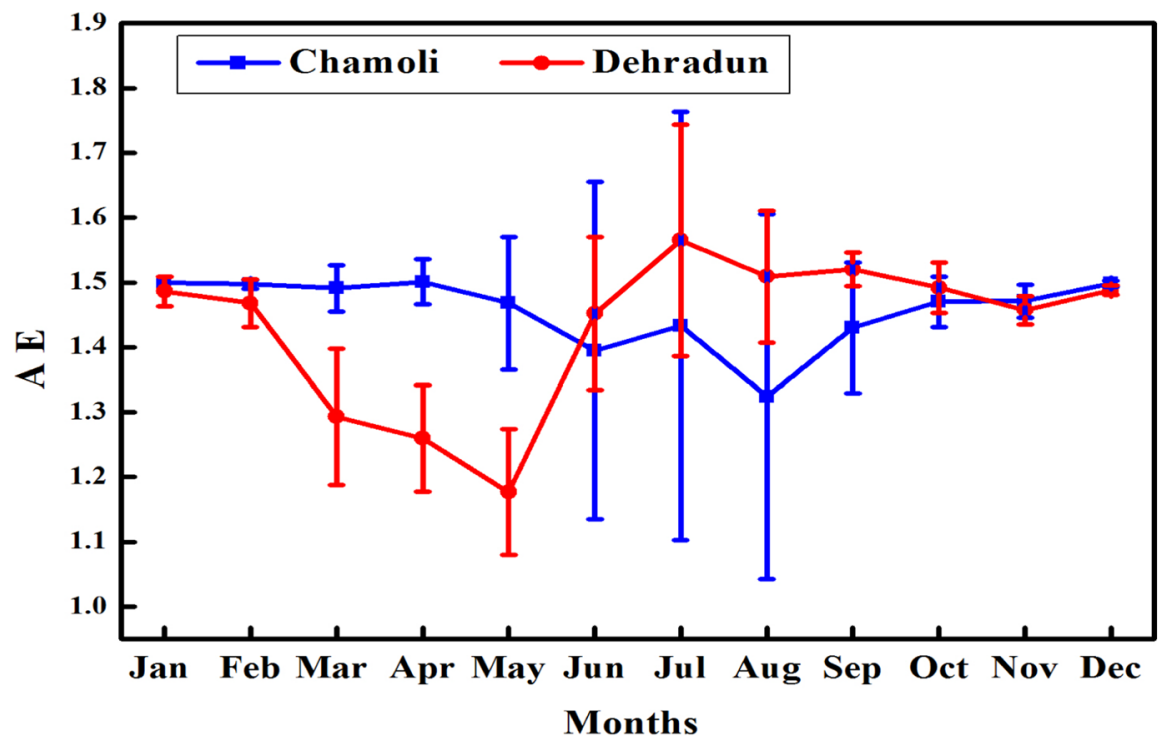

AE over two regions (Fig. 5b) does not show a large seasonal dependence as the values are $>1.4$, in most of the seasons, except a slightly lower value (1.2) for the Dehradun region. Lower AE indicates the mixing of relatively coarser mode particles likely to be transported from trans-boundary distant locations.

The change in AOD (MODIS) on an annual basis has been estimated for selected regions as depicted in Fig. 6. The highest average value 0.199 of AOD was observed in the year 2012 while the lowest average value 0.149 of AOD was observed for the year 2010 for the Dehradun region. On the other hand, the highest average value 0.163 of AOD was found in the year 2012 while the lowest average value 0.08 of AOD was observed in the year 2010 for the Chamoli region. The annual mean for Dehradun varied from about 0.14 to 0.20 over a decade and that for the Chamoli region varied between 0.07 and 0.16 , which indicates that the foothill site itself is having a background level higher than the mountainous terrain throughout the year. The lowest AOD in 2010 for Chamoli and highest AOD in 2012 for Dehradun could be associated with the enhanced episodes of rain and higher frequency of dust transport respectively.

The monthly and annual statistics of AOD and AE are presented in Tables 1 and 2 respectively for selected regions. The maximum AOD (MODIS) was observed as 0.148 in the month of May 2012, and maximum AOD (MISR) was observed as 0.664 in the month of December 2010 for the Dehradun region. On the other hand, the lowest AOD (MODIS) and AOD (MISR) values were observed as 0.043 and 0.053 in the month of December 2012 respectively for the Dehradun region.

Further, the maximum (1.8) and minimum (1.06) $\mathrm{AE}$ values were observed during the months of July 2010 and May 2006 respectively. The high (0.546) and low (0.0215) AOD values were however observed in the month of July 2012 and in January 2006 respectively in district Chamoli. Further, the highest and lowest values of AE were observed as 1.8 in the month of July 2012 and 0.725 in the month of August 2008 respectively for district Chamoli. The high values of $\mathrm{AE}$ are the indicator of the dominance of the fine mode particles during the year, which are primarily originating from local sources.

The data on a number of visitors coming to visit Garhwal Himalaya was obtained from the tourist registration office of Rishikesh for the period 2011-2014. It was revealed from this data that the maximum and minimum numbers of visitors were reported for the years 2011 and 2012, respectively, while it was minimum in the year 2014 (Table 3). However, the June 2013 natural calamity and a big flash flood in Kedarnath and the adjoining Himalayan belt greatly impacted the number of visitors in the subsequent 

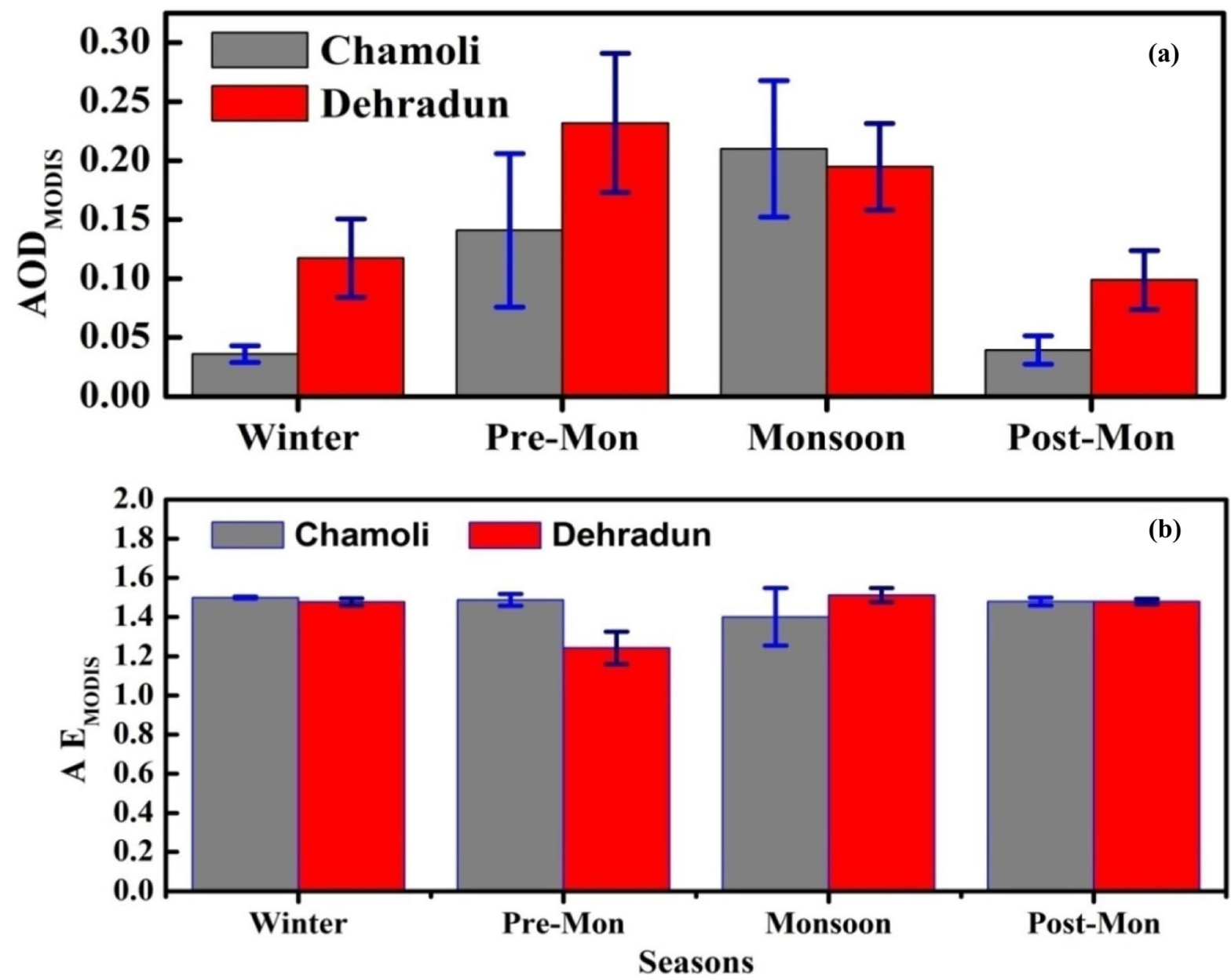

Fig. 5 (a) Average seasonal variation of AOD (b) Average seasonal variation of AE at selected study sites during the study period

years of study. Thus, this account of incidences and corresponding data suggest that an increased number of visitors along with vehicular density increased the anthropogenic activities and had an impact on the status of aerosols in the atmosphere over the study regions.

Frequency distribution of $\mathrm{AE}$

The frequency histogram of AE is presented in Fig. 7, which shows two different frequency modes for both the study areas. In district Chamoli, the frequency distribution of $\mathrm{AE}$ is divided into 12 different categories of 0.1 intervals and the highest $\mathrm{AE}$ observed was for the range 1.4-1.5, which is about 53\% higher as compared to other ranges of AE. In total, we have $45 \%$ of the observations for the range 1.5-1.6, while $4 \%$ of the data is below 0.8 and $5 \%$ of data is above 1.6., suggesting that the distance transport of the pollutants has taken place to about $4 \%$ of the total occurrences. Similarly, the frequency distribution of $\mathrm{AE}$ was divided into 16 different categories for district Dehradun. The maximum value of $\mathrm{AE}$ was observed for a range of $1.45-1.5$, which is about $44 \%$ higher as compared to other ranges of $\mathrm{AE}$. The AE reported for different aerosol types allows the interpretation of the two frequency modes which are present in the measurements (Eck et al., 1999; Hess et al., 1998; Holben et al., 2001). The scatter plot of AOD (440 nm) versus $\mathrm{AE}$ (daily means) is shown in Fig. 8. The colours here 
Fig. 6 Annual variation of AOD (MODIS) at selected sites across the study period

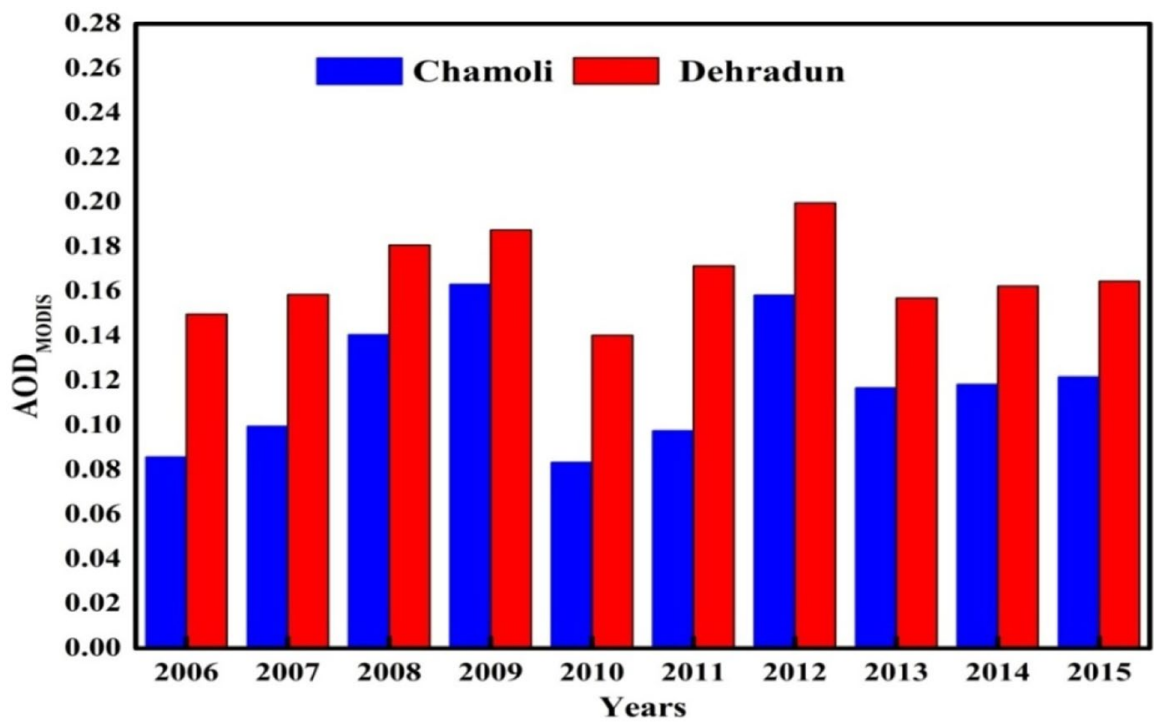

indicate the different types of aerosols. The mean values of AOD and AE ( \pm 1 standard deviation) for each type of aerosols are superimposed.

The possession of higher $\mathrm{AE}$ values over a given location signifies the dominance of fine-sized anthropogenic aerosols which mostly originate from biomass burning and fossil fuel combustion (Holben et al.,
2001; Schuster et al., 2006). In the frequency distribution of $\mathrm{AE}$, the wide range of daily values indicates the presence of various types of aerosols. The lower values of $\mathrm{AE}$ denote the large diameter of the aerosol particles e.g. desert dust, while higher values of the AE mark the presence of fine particles in the ambient environment (i.e. both types of aerosols, resulting from biomass
Fig. 7 Frequency distribution of AE at selected sites in Uttarakhand during the years 2006-2015: (a) Chamoli and (b) Dehradun
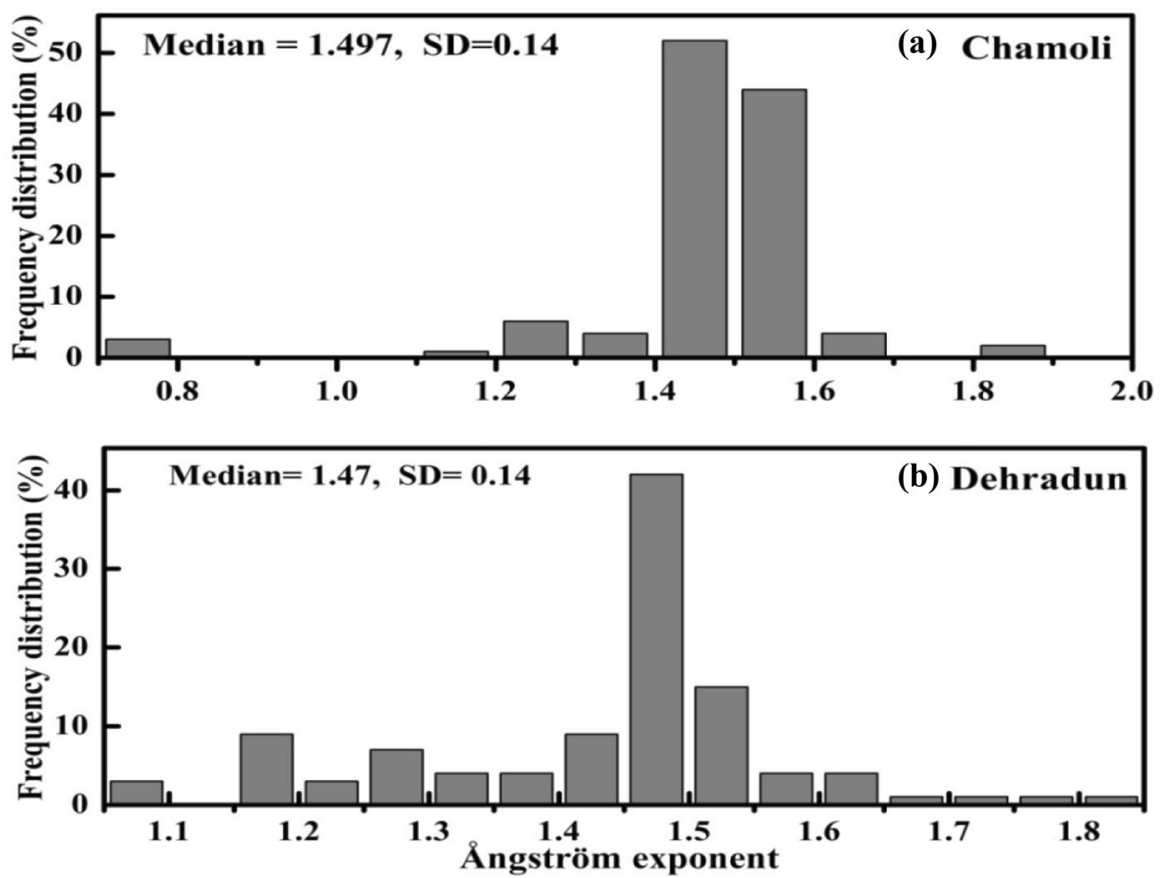


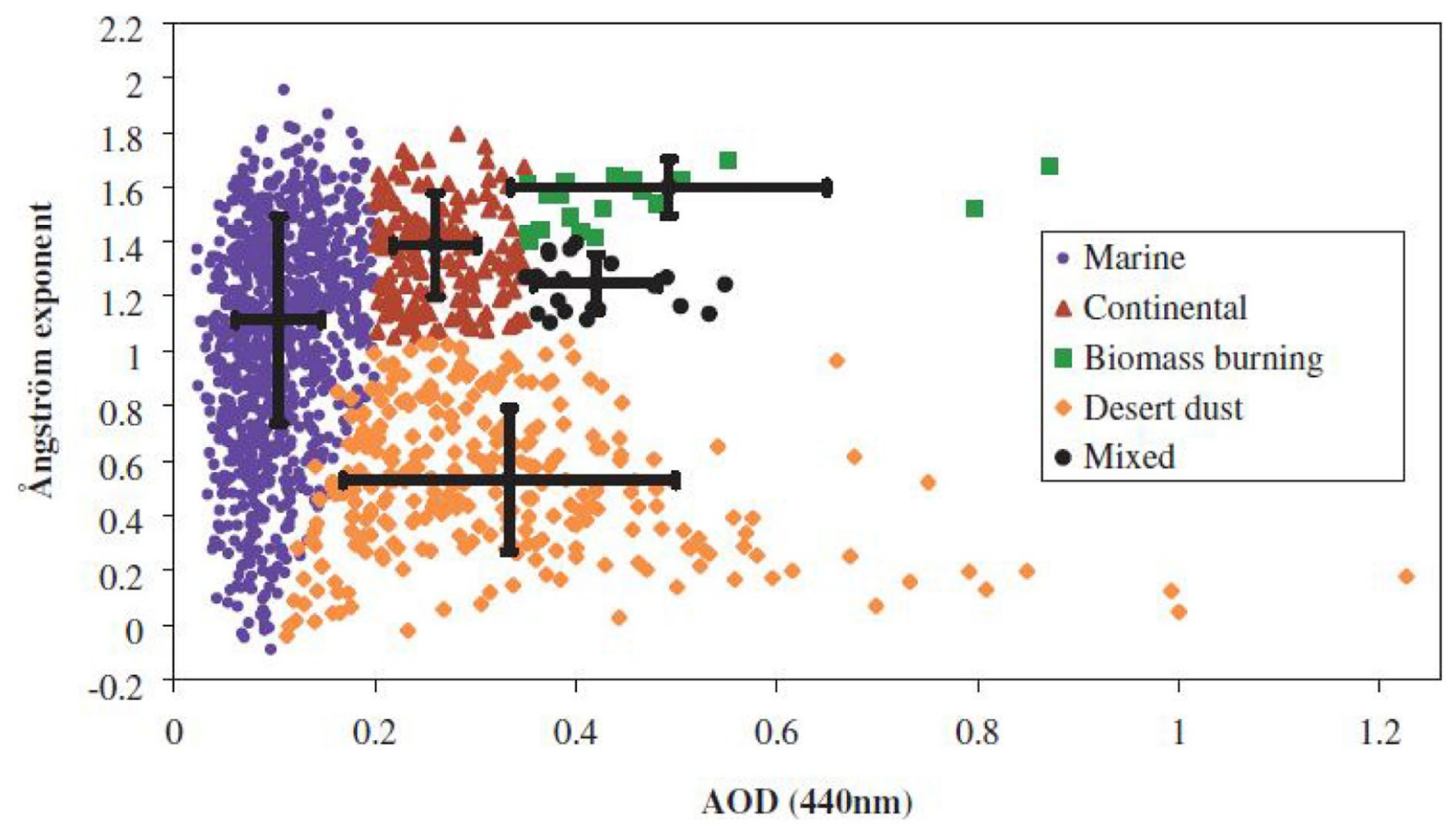

Fig. 8 Scatter plot of AE versus AOD (440 nm) (daily means). Here different colours indicate the different aerosol types and the mean values of $\mathrm{AOD}$ and $\mathrm{AE}( \pm 1$ standard deviation) for each type are superimposed

burning, continental aerosols and other anthropogenic activities). For the months of May, June, July and August (MJJA) for every year, we observed the AOD values in the range of $0.15-0.35$ and $A E$ in the range of 1.2-1.5; this represents the type of particles as continental aerosols or biomass burning (Fig. 8). $\mathrm{AOD}$ and $\mathrm{AE}$ show a significant long-range transportation of aerosols originating from the north-western region along with continental origin, especially during the pre-monsoon and monsoon seasons, when open

Table 1 Monthly statistics of AOD (MODIS \& MISR) and AE (MODIS) observed for district Dehradun during the study period (mean; AV: average, STD: standard deviation, Max: maximum, Min: minimum)

\begin{tabular}{|c|c|c|c|c|c|c|c|c|c|c|c|c|}
\hline \multirow[t]{2}{*}{ Months } & \multicolumn{4}{|c|}{ AOD (MODIS) } & \multicolumn{4}{|c|}{ AOD (MISR) } & \multicolumn{4}{|c|}{ AE (MODIS) } \\
\hline & AV & STD & Max & Min & AV & STD & Max & Min & AV & STD & Max & Min \\
\hline Jan & 0.097 & 0.038 & 0.161 & 0.053 & 0.150 & 0.056 & 0.239 & 0.095 & 1.486 & 0.023 & 1.531 & 1.464 \\
\hline Feb & 0.138 & 0.038 & 0.226 & 0.098 & 0.203 & 0.074 & 0.361 & 0.115 & 1.468 & 0.037 & 1.519 & 1.412 \\
\hline Mar & 0.155 & 0.063 & 0.260 & 0.082 & 0.264 & 0.085 & 0.400 & 0.123 & 1.293 & 0.105 & 1.446 & 1.177 \\
\hline Apr & 0.212 & 0.069 & 0.339 & 0.088 & 0.235 & 0.055 & 0.312 & 0.147 & 1.260 & 0.082 & 1.439 & 1.169 \\
\hline May & 0.328 & 0.083 & 0.486 & 0.218 & 0.399 & 0.124 & 0.587 & 0.208 & 1.177 & 0.097 & 1.326 & 1.068 \\
\hline Jun & 0.308 & 0.060 & 0.421 & 0.233 & 0.324 & 0.157 & 0.664 & 0.182 & 1.452 & 0.118 & 1.725 & 1.340 \\
\hline Jul & 0.228 & 0.106 & 0.416 & 0.080 & 0.369 & 0.187 & 0.476 & 0.090 & 1.565 & 0.179 & 1.800 & 1.200 \\
\hline Aug & 0.121 & 0.041 & 0.186 & 0.061 & 0.296 & 0.150 & 0.562 & 0.149 & 1.509 & 0.102 & 1.650 & 1.297 \\
\hline Sep & 0.123 & 0.048 & 0.190 & 0.045 & 0.244 & 0.085 & 0.366 & 0.133 & 1.520 & 0.026 & 1.551 & 1.484 \\
\hline Oct & 0.128 & 0.053 & 0.211 & 0.055 & 0.226 & 0.103 & 0.468 & 0.125 & 1.492 & 0.039 & 1.555 & 1.449 \\
\hline Nov & 0.098 & 0.033 & 0.141 & 0.055 & 0.184 & 0.050 & 0.284 & 0.123 & 1.457 & 0.022 & 1.483 & 1.403 \\
\hline Dec & 0.071 & 0.018 & 0.114 & 0.043 & 0.136 & 0.064 & 0.261 & 0.053 & 1.488 & 0.007 & 1.500 & 1.478 \\
\hline
\end{tabular}


Table 2 Monthly average variation of AOD (MODIS) and AE (MODIS) in Chamoli

\begin{tabular}{|c|c|c|c|c|c|c|c|c|}
\hline \multirow[t]{2}{*}{ Months } & \multicolumn{4}{|c|}{ AOD (MODIS) } & \multicolumn{4}{|l|}{$\mathrm{AE}$} \\
\hline & $\mathrm{Av}$ & SD & Max & Min & $\mathrm{Av}$ & SD & Max & Min \\
\hline Jan & 0.027 & 0.005 & 0.038 & 0.005 & 1.500 & 0.000 & 1.501 & 1.500 \\
\hline Feb & 0.045 & 0.011 & 0.067 & 0.011 & 1.497 & 0.007 & 1.509 & 1.483 \\
\hline Mar & 0.070 & 0.031 & 0.119 & 0.031 & 1.491 & 0.036 & 1.553 & 1.424 \\
\hline Apr & 0.151 & 0.120 & 0.457 & 0.054 & 1.501 & 0.035 & 1.561 & 1.438 \\
\hline May & 0.201 & 0.091 & 0.427 & 0.091 & 1.468 & 0.102 & 1.603 & 1.239 \\
\hline Jun & 0.248 & 0.083 & 0.382 & 0.083 & 1.395 & 0.260 & 1.648 & 0.746 \\
\hline Jul & 0.314 & 0.164 & 0.546 & 0.107 & 1.433 & 0.330 & 1.800 & 0.750 \\
\hline Aug & 0.213 & 0.105 & 0.378 & 0.074 & 1.324 & 0.281 & 1.500 & 0.725 \\
\hline Sep & 0.093 & 0.036 & 0.142 & 0.036 & 1.430 & 0.101 & 1.517 & 1.188 \\
\hline Oct & 0.052 & 0.021 & 0.082 & 0.021 & 1.470 & 0.039 & 1.504 & 1.375 \\
\hline Nov & 0.041 & 0.015 & 0.066 & 0.015 & 1.471 & 0.025 & 1.499 & 1.415 \\
\hline Dec & 0.025 & 0.006 & 0.041 & 0.006 & 1.498 & 0.005 & 1.501 & 1.485 \\
\hline
\end{tabular}

agricultural residue burning is rampant. Figure 8 also shows that the desert dust is present in various sizes of particles, widespread and well mixed higher up in the atmosphere, though the mixed aerosols are having particles of fine to coarse mode but confined to low AOD values. Continental aerosols are mainly of fine mode type along with a marked presence of aerosols resulting from biomass burning.

The present results are also compared with the various other investigations performed in different regions and are presented in Table 4.

Table 3 Number of visitors in Garhwal region ( source: Rishikesh tourist office, Rishikesh, Uttarakhand)

\begin{tabular}{lllll}
\hline Months/years & \multicolumn{4}{l}{ Number of visitors } \\
\cline { 2 - 5 } & 2011 & 2012 & 2013 & 2014 \\
\hline Jan & 19,186 & 22,122 & 18,464 & 13,402 \\
Feb & 18,508 & 20,620 & 18,687 & 13,916 \\
Mar & 23,138 & 23,215 & 22,291 & 19,788 \\
Apr & 30,417 & 40,409 & 14,535 & 19,888 \\
May & 89,340 & 70,623 & 74,476 & 26,188 \\
Jun & 558,411 & 252,766 & 115,854 & 37,883 \\
Jul & 148,708 & 168,161 & 19,244 & 30,143 \\
Aug & 198,693 & 68,686 & 26,335 & 30,696 \\
Sep & 28,706 & 13,219 & 12,599 & 71,680 \\
Oct & 29,123 & 25,092 & 12,553 & 23,941 \\
Nov & 20,817 & 9546 & 12,819 & 23,379 \\
Dec & 21,480 & 15,447 & 15,867 & 21,011 \\
Total & $1,186,527$ & 729,906 & 363,724 & 331,915 \\
\hline
\end{tabular}

CALIPSO and HYSPLIT air mass trajectory investigation

The air mass trajectories were computed and correlated with trajectories obtained from CALIPSO data at different altitudes, as discussed below.

\section{Chamoli district}

Days with the highest values of AOD were selected for Chamoli during the period of study. In order to study the expected long-range transport of aerosols from a distant location to this study site, 5-day isentropic air mass back trajectories were calculated using a hybrid (Eulerian and Lagrangian) HYSPLIT model. Figure $9 \mathrm{a}-\mathrm{f}$ represent back trajectories reaching at Chamoli region on 02 April 2008, 24 April 2009, 30 June 2010, 17 May 2011, 26 May 2012 and 07 June 2015 respectively. Back trajectories (in black line) of 5 days (with yellow dots) are draped over MODIS active fire activities (with red dots). The aerosol types identified by CALIPSO near the regions of our site include dust and dust aerosols dominated by anthropogenic aerosols.

Image of dust storm derived from CALIPSO is also shown in Fig. 10a-f. The nearest and coincident CALIPSO which passes over the given days here is found to show the presence of enhanced dust along with polluted dust in the column of atmosphere to about $5 \mathrm{~km}$ in the vertical. The peak value of AOD 
Table 4 Annual AOD (MODIS) at $550 \mathrm{~nm}$ and AE for different places throughout the globe

\begin{tabular}{lllll}
\hline Study location & Study period & AOD (MODIS) & AE & Reference \\
\hline Kazakhstan & $2002-2017$ & $0.17 \pm 0.09$ & $1.29 \pm 0.17$ & Rupakheti et al. (2019) \\
Turkmenistan & $2002-2017$ & $0.11 \pm 0.13$ & $1.41 \pm 0.13$ & Rupakheti et al. (2019) \\
Uzbekistan & $2002-2017$ & $0.18 \pm 0.09$ & $1.18 \pm 0.24$ & Rupakheti et al. (2019) \\
Tajikistan & $2002-2017$ & $0.17 \pm 0.14$ & $1.36 \pm 0.18$ & Rupakheti et al. (2019) \\
Kolkata & $2001-2017$ & $0.68 \pm 0.18$ & & Mao et al. (2014) \\
Russia & $2000-2018$ & $0.17 \pm 0.12$ & $1.31 \pm 0.27$ & Filonchyk et al. (2019a, b) \\
Czech Republic & $2000-2018$ & $0.24 \pm 0.14$ & $1.31 \pm 0.33$ & Filonchyk et al. (2019a, b) \\
Delhi & $2001-2012$ & $0.81 \pm 0.2$ & & Lodhi et al. (2013) \\
\hline
\end{tabular}

(0.79) was observed on 24 April 2009. The air trajectory is shown to pass through the dust region that originated in Afghanistan (Kabul) on 22 April 2009 (Fig. 10b) and subsequently moved via Punjab. The CALIPSO pass was also available at the same time in the night (nearest time). Figure 9 shows that this trajectory passed through Iran, Afghanistan,
Pakistan and Punjab and reached the study site (Chamoli). This indicates that due to westerly flow, passing over Afghanistan played a major role in building the elevated aerosol layer. The transported aerosols affected the dust aerosols loading on 24 April 2009 over Chamoli. In general, the dust episode usually occurs in the early spring (Solanki et al., 2013) and

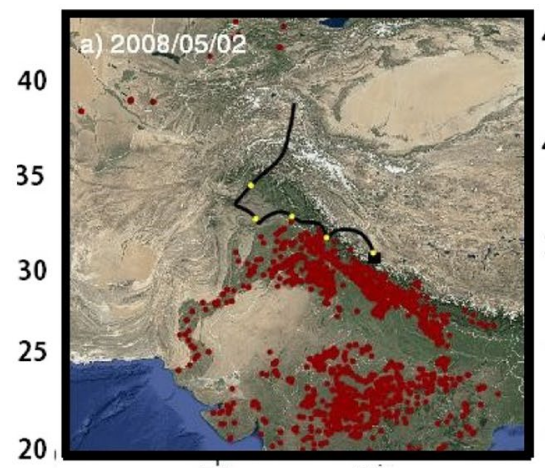

20

70

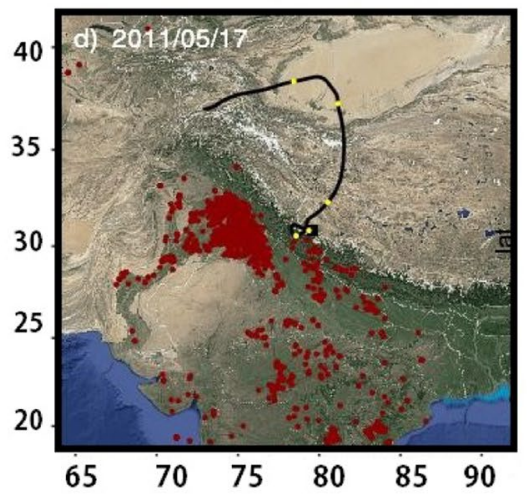

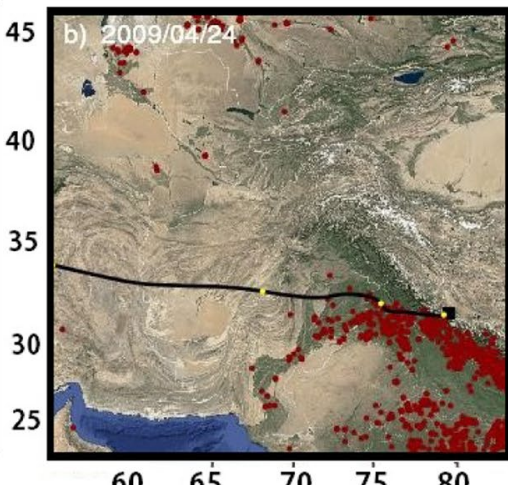

$\begin{array}{lllll}60 & 65 & 70 & 75 & 80\end{array}$

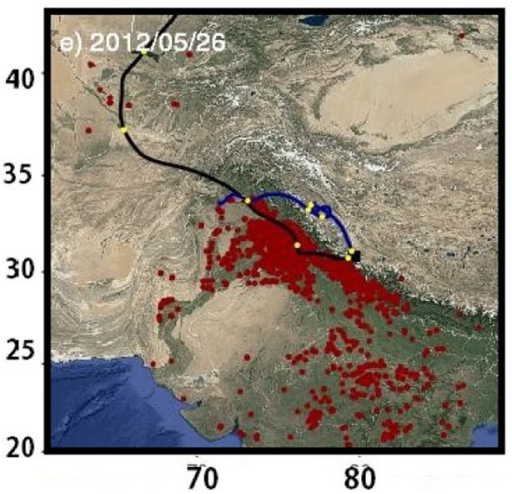

Longitude
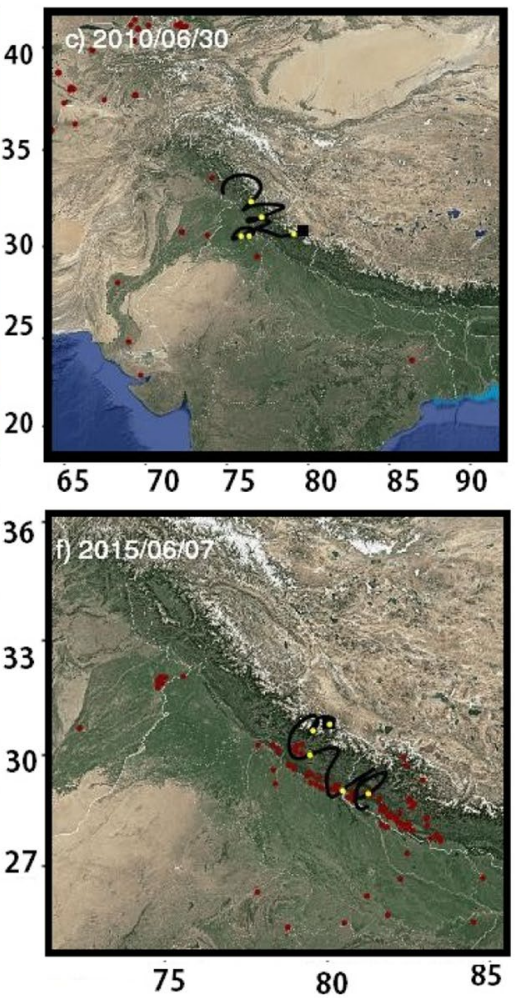

Fig. 9 Five-day back trajectories draped on MODIS active fire sites in the same duration on specific days when the recorded AOD is maximum (Chamoli region) 
summer until the arrival of the monsoon. According to a study carried out by Guleria et al. (2011), the dust storms in Mohal, Kullu and Himachal Pradesh started in April and remained until June.

The peak value of AOD (0.64) was found on 26 May 2012. The air parcel which passes from the dust episode which originated in Afghanistan (Kabul) on 25 May 2012 (Fig. 10e) came from Punjab, and CALIPSO pass was available on 25 May in the nighttime (nearest time). Thereafter, this trajectory has passed through Islamabad and Himachal Pradesh and reached the Chamoli region.

\section{Dehradun region}

Figures $11 \mathrm{a}-\mathrm{f}$ and $12 \mathrm{a}-\mathrm{f}$ show the air mass back trajectories and CALIPSO-derived images of a dust storm for the Dehradun region. The CALIPSOderived images (Fig. 12) identify the dust aerosols along the overpass air mass back trajectories. The highest value of AOD (0.78) was found on 26 April 2009. The air parcel that passes through the dust storm originated in Afghanistan (Kabul) on 23 April 2009 (Fig. 12a) that came from Iran, and CALIPSO pass was available at that time (nighttime). The figure shows that the air mass trajectories have passed through Iraq, Iran, Afghanistan (Kabul), Pakistan (Islamabad) and Jammu \& Kashmir and reached the study region (Dehradun). Westerlies bring the dust along with them and occasionally form the elevated aerosol layers that enhance the aerosol loading in this region. Figure 12 shows the enhanced dust column along with the presence of polluted dust. The transported dust may have thus affected the aerosols loading on 26 April 2009 over the Dehradun region. Similarly, the highest value of AOD (0.8) was found on 18 May 2012. The air parcel passes from the dust region that originated in Iran on 14 May 2012 (Fig. 12a), and CALIPSO pass was available on a nearest time (nighttime). Thereafter, this trajectory has passed through

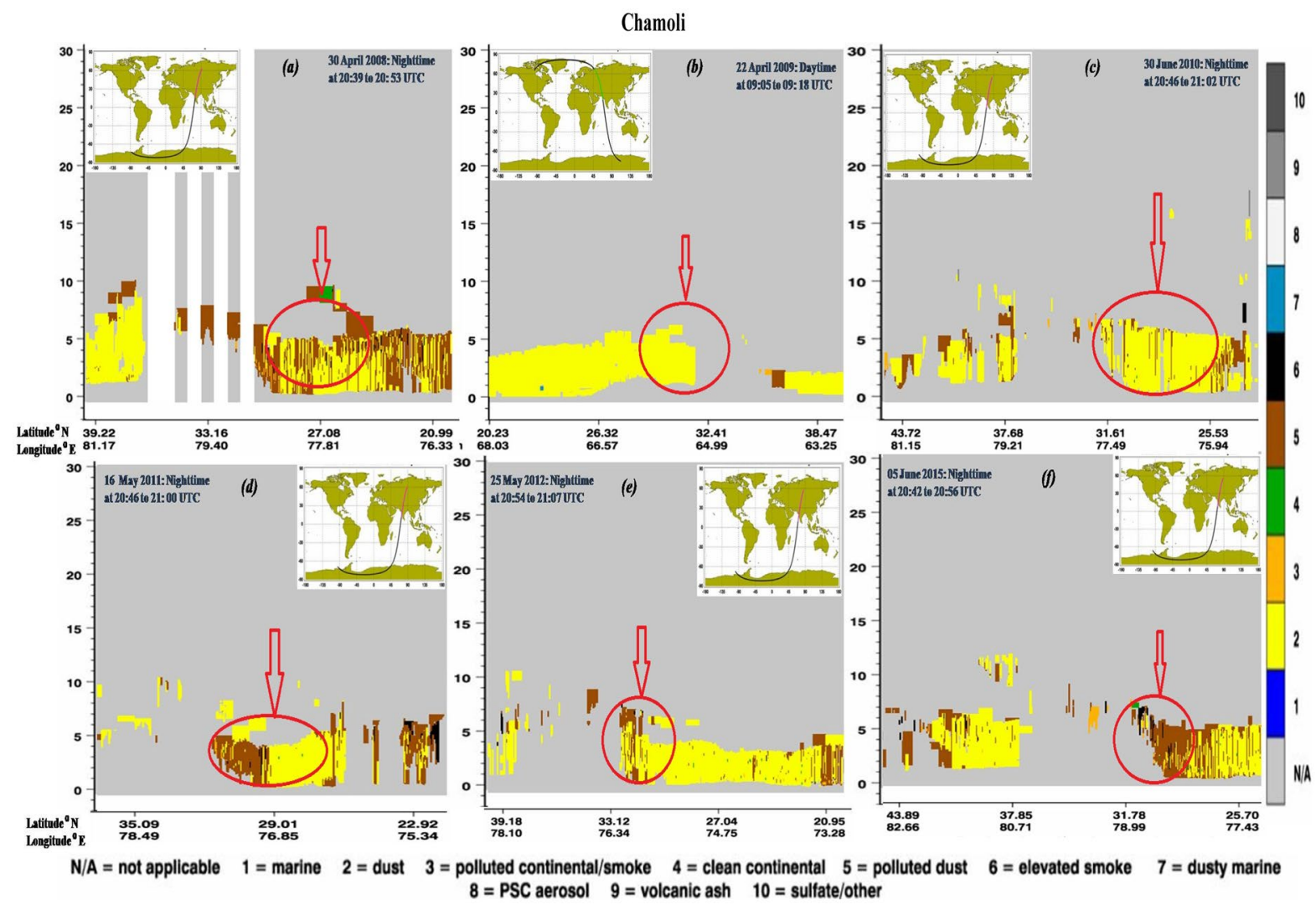

Fig. 10 A CALIPSO-derived vertical feature mask image (version: 3.30) indicating high aerosols at the Chamoli region in specific days. The insets in all the images mark the CALIPSO overpass on respective days 

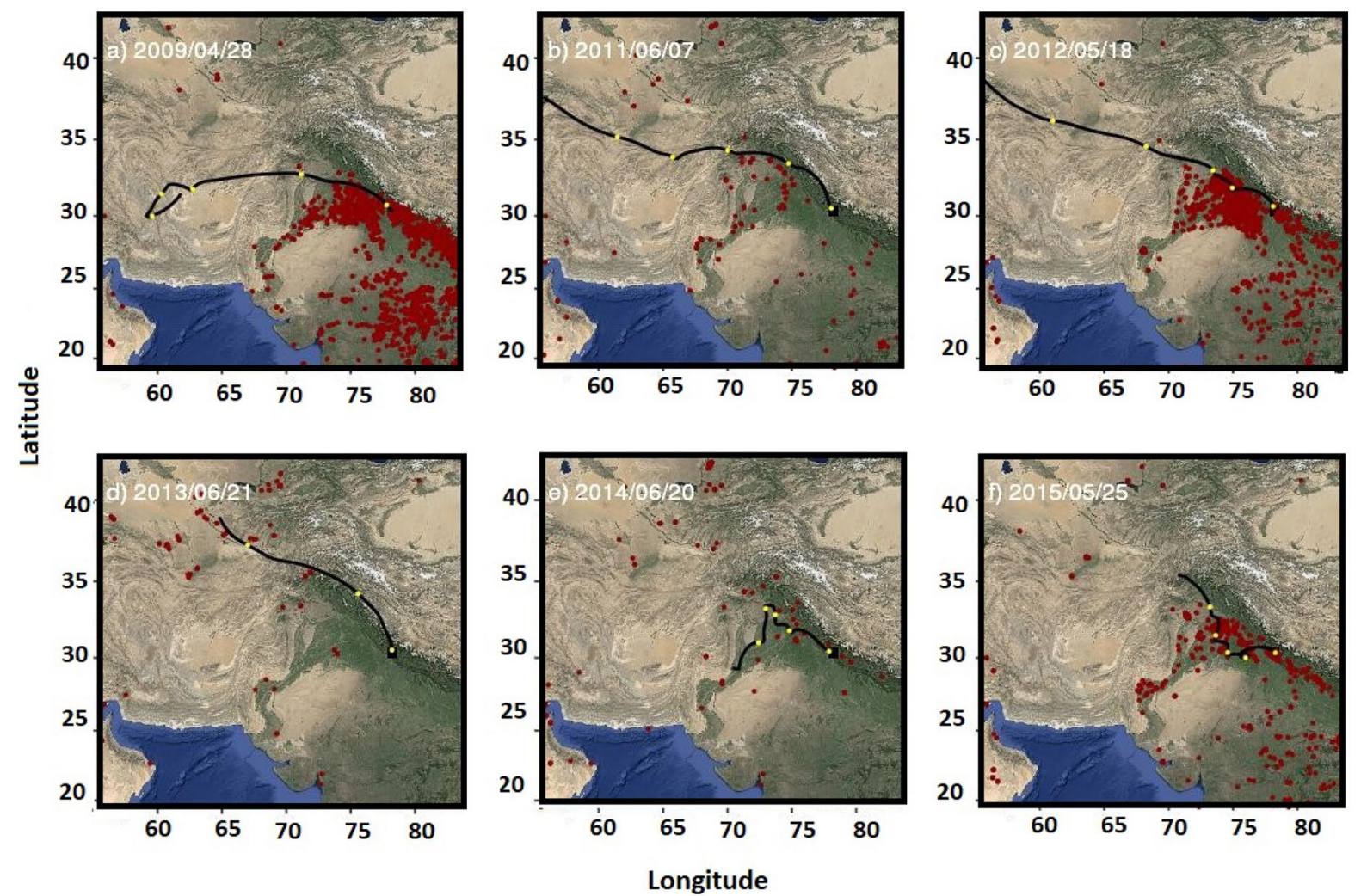

Fig. 11 Five-day back trajectories draped on MODIS active fire sites in the same duration on specific days when recorded AOD was maximum for the Dehradun site

Turkmenistan, Iran, Afghanistan (Kabul), (Pakistan) Islamabad and Jammu \& Kashmir and finally reached the site (Dehradun region). The adjacent plains and the Himalayan foothills encountered the episodes of enhanced dust contributing to higher levels of aerosols during the pre-monsoon season (Kumar et al., 2014). Further, Deep et al. (2019) have observed that most of the time during summer months (May 2012), the air mass was from semiarid dry regions of the West which suggests that the coarse particles were transported with the westerlies approaching Dehradun region. According to Patel and Kumar (2015), the dust episodes are periodic events over India especially in the Northern region. The study of Patel and Kumar (2015) also supports the observations made in the present study.
In the present study, an attempt is also made to find out the statistical relationship between AOD values obtained with two different satellites. For the same purpose, we have calculated Pearson's correlation coefficient and direction of the linear relationship. The limit of correlation coefficient varied between +1 and -1 inclusive. The correlation is only applicable to linear relationships and has been calculated for all data obtained on the monthly basis (Fig. 13). Comparison of results indicates a significant positive linear correlation (i.e. 0.73) between monthly datasets for both i.e. for MODIS and MISR (AOD) data. However, such correlation $(r=0.747)$ was found for the data observed in China which is in close agreement with our observations. 


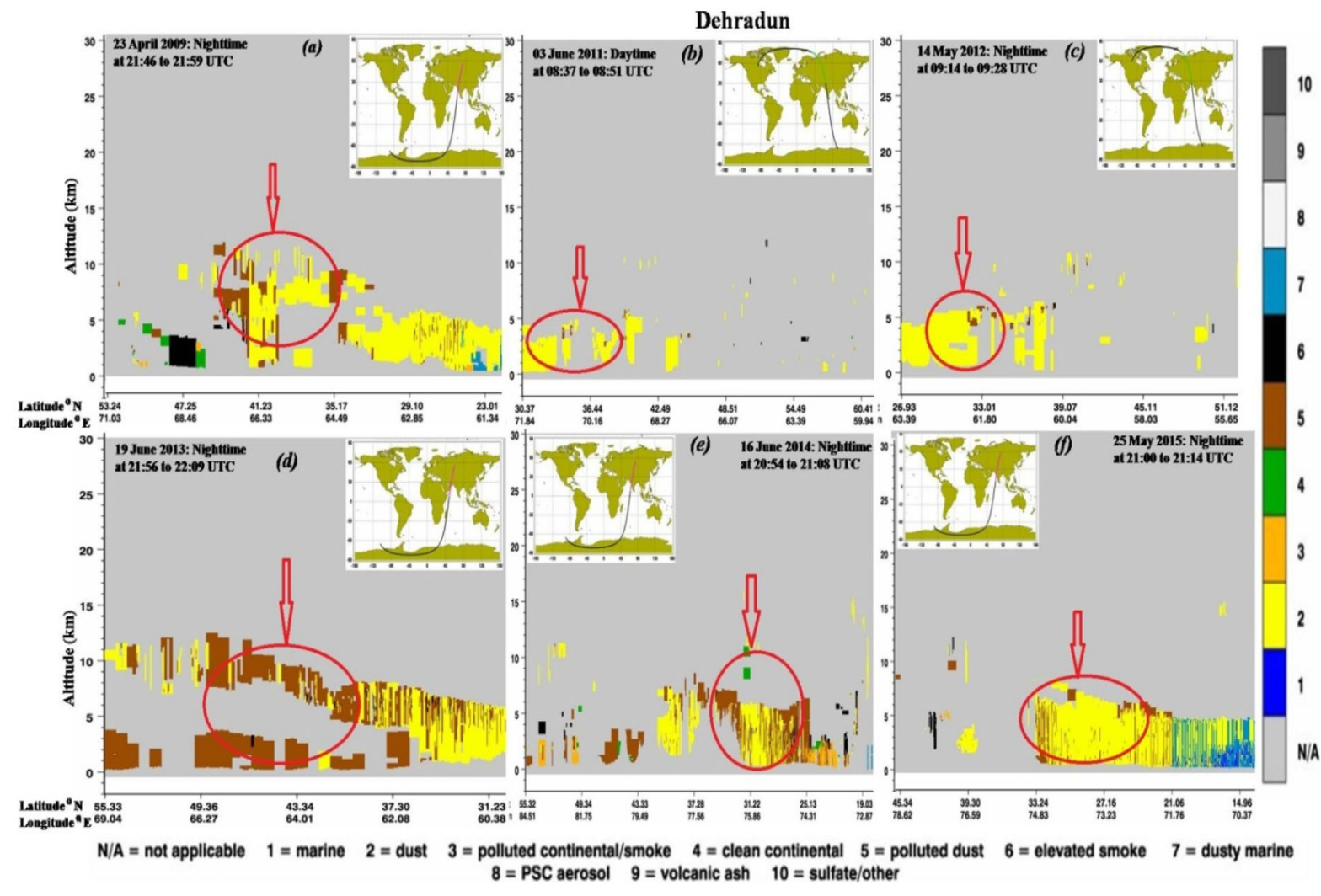

Fig. 12 A CALIPSO-derived vertical feature mask image (version: 3.30) indicating high-concentration aerosols at Dehradun region in specific days. The insets in all the images mark the CALIPSO overpass on respective days

Fig. 13 Scatter plots representing validation of MODIS AOD against MISR AOD retrieved at wavelength $550 \mathrm{~nm}$ over the Dehradun region

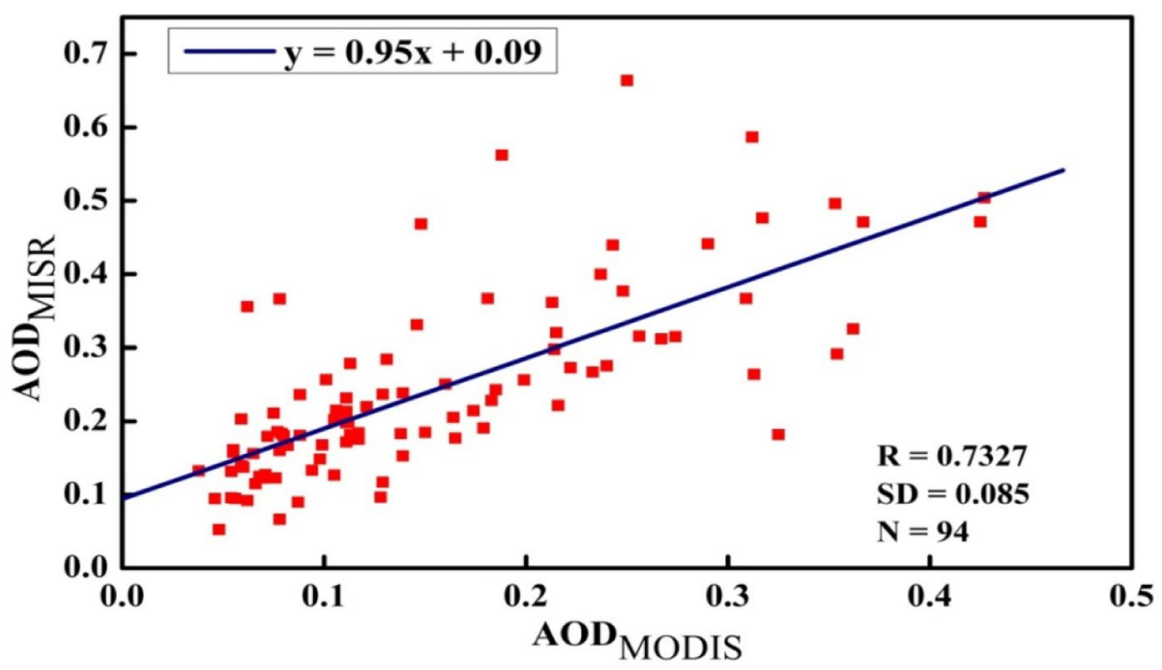




\section{Summary and conclusions}

The present study is dedicated to the satellite observation (MODIS and MISR)-based AOD analysis over two different locations in the southern slope of northern Indian Himalaya. CALIPSO imageries along with the HYSPLIT air trajectory model were used to investigate possible source apportionment of aerosols in this region. Two sites viz. Chamoli (higher Himalaya) and Dehradun (Himalayan foothills) with different altitudes, geography and topography were selected. Detailed statistical analysis of acquired data was performed from the years from 2006 to 2015 .

The monthly average value of AOD was found to increase from January to July in Chamoli and from January to June in Dehradun district. However, AOD decreases during the monsoon and winter months. The highest value of AOD was found in the pre-monsoon season in Dehradun and in monsoon season in Chamoli. A similar trend has also been reported by Sagar et al. (2004) for Manora Peak in Nainital and by Sharma et al. (2012) in Himachal Pradesh (neighbouring state of Uttarakhand). The slightly higher value of the AOD in Chamoli in early monsoon season may be attributed to the higher number of pilgrims visiting the holy shrines in Himalaya. This might be the primary cause that leads to the enhanced AOD in the monsoon season over the Chamoli region. Contrary to the pattern of variation of $\mathrm{AOD}$, the value of $\mathrm{AE}$ was observed higher during the peak monsoon period in the Dehradun region and during winter in the Chamoli region. This difference might be due to the difference in the prevailing meteorology along these two altitudes in the Himalayan region. The comparison in AOD retrieved with MODIS and MISR demonstrated a positive correlation of 0.73 . The value of $\mathrm{AE}$ lies between 0.9 and 1.9, which further indicates that there are different types of aerosols in the Dehradun region. The maximum value of $\mathrm{AE}$ is observed in the range of $1.45-1.5$, which is about $44 \%$ more as compared to other ranges of $\mathrm{AE}$. However, the value of $\mathrm{AE}$ in Chamoli region lies between 0.7 and 1.8. The highest $\mathrm{AE}$ is found in the range of 1.4-1.5, which is about 53\% higher as compared to other ranges of AE. However, the range $1.5-1.6$ has about $45 \%$ of the total observations. The coarse-mode aerosol particles are found to be dominant in the pre-monsoon season while fine-mode particles are dominant during the winter season in study regions. The 5-day isentropic air mass back trajectory analysis also shows that the western (arid) regions of Iraq, Iran, Afghanistan and Pakistan are major contributors of atmospheric aerosols and the mineral dust during the pre-monsoon.

It is important to highlight the uncertainty, limitations and future prospects of our present investigation. MODIS and MISR data sets are available with different spatial resolutions; further internal algorithms for data retrieval also differ for both of these instruments. CALIPSO images are an excellent tool in understanding the overall loading of aerosols on a regional scale. Besides the limitations in resolving at the district level, CALIPSO is still the only possible way to provide the 3D perspective of aerosol distribution in the region, thus contributing to the source apportionment analysis. The HYSPLIT model is considered to be one of the most extensively used atmospheric transport and dispersion models in the atmospheric science community, and within limitations, this model is capable of providing an essential glance regarding the pollutant transportation pathways towards the region of our interest. In an ongoing investigation, in situ observations coupled with aerosol transport models might be used for a deeper understanding of aerosol characteristics of the Himalayan foothills located in the vicinity of the Indo-Gangetic Basin which has been identified as one of the most populated and polluted regions throughout the globe.

Acknowledgements The authors would like to thank NOAA Air Resources Laboratory for the provision of the HYSPLIT transport and dispersion model and NASA Langley. The authors would like to thank "NASA (The National Aeronautics and Space Administration)" for providing the data for this study. We are indebted to two anonymous reviewers for their valuable comments and suggestions.

$\mathrm{AD}$ was financially assisted by the University Grants Commission (UGC), New Delhi, under Campus Fellowship program for $\mathrm{Ph} . \mathrm{D}$.

Data availability The data that support the findings of this study are available, open and free to the public and can be downloaded from the website https://giovanni.sci.gsfc.nasa. gov/giovanni/.

\section{References}

Anchordoqui, L. A., Chudnovsky, E. M., \& Paul, T. C. (2020). Risk assessment of COVID-19 airborne infection during hybrid learning. Med Rxiv.

Adesina, A. J., Kumar, K. R., Sivakumar, V., \& Piketh, S. J. (2016). Intercomparison and assessment of long-term (2004 2013) multiple satellite aerosol products over two contrasting 
sites in South Africa. Journal of Atmospheric and Solar-Terrestrial Physics, 148, 82-95.

Boiyo, R., Kumar, K. R., \& Zhao, T. (2018). Spatial variations and trends in AOD climatology over East Africa during 2002-2016: A comparative study using three satellite data sets. International Journal of Climatology, 38, e1221-e1240.

Brunekreef, B., \& Holgate, S. T. (2002). Air pollution and health. The lancet, 360(9341), 1233-1242.

Cachorro, V. E., Durán, P., Vergaz, R., \& de Frutos, A. M. (2000). Columnar physical and radiative properties of atmospheric aerosols in north central Spain. Journal of Geophysical Research: Atmospheres, 105(D6), 7161-7175.

Chen, Q. X., Huang, C. L., Yuan, Y., Mao, Q. J., \& Tan, H. P. (2020). Spatiotemporal distribution of major aerosol types over China based on MODIS products between 2008 and 2017. Atmosphere, 11(7), 703.

Cohen, A. J., Brauer, M., Burnett, R., Anderson, H. R., Frostad, J., Estep, K., \& Forouzanfar, M. H. (2017). Estimates and 25 -year trends of the global burden of disease attributable to ambient air pollution: An analysis of data from the Global Burden of Diseases Study 2015. The Lancet, 389(10082), 1907-1918.

Dammann, K. W., Hollmann, R., \& Stuhlmann, R. (2002). Study of aerosol impact on the earth radiation budget with satellite data. Advances in Space Research, 29(11), 1753-1757.

Deep, A., Pandey, C. P., Nandan, H., Purohit, K. D., Singh, N., Singh, J., \& Ojha, N. (2019). Evaluation of ambient air quality in Dehradun city during 2011-2014. Journal of Earth System Science, 128(4), 96.

Dey, S., \& Di Girolamo, L. (2010). A climatology of aerosol optical and microphysical properties over the Indian subcontinent from 9 years (2000-2008) of Multiangle Imaging Spectroradiometer (MISR) data. Journal of Geophysical Research: Atmospheres, 115(D15).

Dhaka, S. K., Kumar, V., Panwar, V., Dimri, A. P., Singh, N., Patra, P. K., \& Hayashida, S. (2020). PM 2.5 diminution and haze events over Delhi during the COVID-19 lockdown period: an interplay between the baseline pollution and meteorology. Scientific Reports, 10(1), 1-8.

Dominici, F., Peng, R. D., Bell, M. L., Pham, L., McDermott, A., Zeger, S. L., \& Samet, J. M. (2006). Fine particulate air pollution and hospital admission for cardiovascular and respiratory diseases. JAMA, 295(10), 1127-1134.

Eck, T. F., Holben, B. N., Reid, J. S., Dubovik, O., Smirnov, A., O'neill, N. T., \& Kinne, S. (1999). Wavelength dependence of the optical depth of biomass burning, urban, and desert dust aerosols. Journal of Geophysical Research: Atmospheres, 104(D24), 31333-31349.

Filonchyk, M., Yan, H., Zhang, Z., Yang, S., Li, W., \& Li, Y. (2019a). Combined use of satellite and surface observations to study aerosol optical depth in different regions of China. Scientific reports, 9(1), 1-15.

Filonchyk, M., Yan, H., \& Zhang, Z. (2019b). Analysis of spatial and temporal variability of aerosol optical depth over China using MODIS combined Dark Target and Deep Blue product. Theoretical and Applied Climatology, 137(3-4), 2271-2288.

Gakidou, E., Afshin, A., Abajobir, A. A., Abate, K. H., Abbafati, C., Abbas, K. M., Abd-Allah, F., Abdulle,
A. M., Abera, S. F., Aboyans, V., et al. (2017). Global, regional, and national comparative risk assessment of 84 behavioural, environmental and occupational, and metabolic risks or clusters of risks, 1990-2016: A systematic analysis for the Global Burden of Disease Study 2016. Lancet, 390, 1345-1422.

Guleria, R. P., Kuniyal, J. C., Rawat, P. S., Thakur, H. K., Sharma, M., Sharma, N. L., \& Dhyani, P. P. (2011). Aerosols optical properties in dynamic atmosphere in the northwestern part of the Indian Himalaya: A comparative study from ground and satellite based observations. Atmospheric Research, 101(3), 726-738.

Guleria, R. P., Kuniyal, J. C., Sharma, N. L., \& Dhyani, P. P. (2012). Seasonal variability in aerosol optical and physical characteristics estimated using the application of the Angström formula over Mohal in the northwestern Himalaya, India. Journal of earth system science, 121(3), 697-710.

Habib, A., Chen, B., Khalid, B., Tan, S., Che, H., Mahmood, T., \& Butt, M. T. (2019). Estimation and inter-comparison of dust aerosols based on MODIS, MISR and AERONET retrievals over Asian desert regions. Journal of Environmental Sciences, 76, 154-166.

Hansen, J., Fung, I., Lacis, A., Rind, D., Lebedeff, S., Ruedy, R., \& Stone, P. (1988). Global climate changes as forecast by Goddard Institute for Space Studies three-dimensional model. Journal of geophysical research: Atmospheres, 93(D8), 9341-9364.

Hess, M., Koepke, P., \& Schult, I. (1998). Optical properties of aerosols and clouds: The software package OPAC. Bulletin of the American Meteorological Society, 79(5), 831-844.

Holben, B. N., Tanre, D., Smirnov, A., Eck, T. F., Slutsker, I., Abuhassan, N., \& Zibordi, G. (2001). An emerging ground-based aerosol climatology: Aerosol optical depth from AERONET. Journal of Geophysical Research: Atmospheres, 106(D11), 12067-12097.

Hu, K., Kumar, K. R., Kang, N., Boiyo, R., \& Wu, J. (2018). Spatiotemporal characteristics of aerosols and their trends over mainland China with the recent Collection 6 MODIS and OMI satellite datasets. Environmental Science and Pollution Research, 25(7), 6909-6927.

Huang, J., Bu, L., Kumar, K. R., Khan, R., \& Devi, N. L. (2020). Investigating the relationship between aerosol and cloud optical properties inferred from the MODIS sensor in recent decades over East China. Atmospheric Environment, 239, 117812.

Huang, J., Minnis, P., Chen, B., Huang, Z., Liu, Z., Zhao, Q., \& Ayers, J. K. (2008). Long-range transport and vertical structure of Asian dust from CALIPSO and surface measurements during PACDEX. Journal of Geophysical Research: Atmospheres, 113(D23).

IPCC (Intergovernmental Panel on Climate Change), Climate Change (2001). The Scientific Basis. Cambridge Uni. Press. 239-287.

Javadinejad, S., Dara, R., \& Jafary, F. (2020). Climate change scenarios and effects on snow-melt runoff. Civil Engineering Journal, 6(9), 1715-1725.

Kanakidou, M., Seinfeld, J. H., Pandis, S. N., Barnes, I., Dentener, F. J., Facchini, M. C., \& Swietlicki, E. (2005). Organic aerosol and global climate modelling: A review. 
Atmospheric Chemistry and Physics, 5(4), 1053-1123. https://doi.org/10.5194/acp-5-1053-2005

Kaskaoutis, D. G., Kambezidis, H. D., Hatzianastassiou, N., Kosmopoulos, P. G., \& Badarinath, K. V. S. (2007). Aerosol climatology: Dependence of the Angstrom exponent on wavelength over four AERONET sites. Atmospheric Chemistry and Physics Discussions, 7(3), 7347-7397.

Kaufman, Y. J., Tanré, D., \& Boucher, O. (2002). A satellite view of aerosols in the climate system. Nature, 419(6903), 215.

Kumar, A., Singh, N., \& Solanki, R. (2018a). Evaluation and utilization of MODIS and CALIPSO aerosol retrievals over a complex terrain in Himalaya. Remote Sensing of Environment, 206, 139-155.

Kumar, K. R., Boiyo, R., Madina, A., \& Kang, N. (2018b). A 13-year climatological study on the variations of aerosol and cloud properties over Kazakhstan from remotely sensed satellite observations. Journal of Atmospheric and Solar-Terrestrial Physics, 179, 55-68.

Kumar, K. R., Sivakumar, V., Yin, Y., Reddy, R. R., Kang, N., Diao, Y., \& Yu, X. (2014). Long-term (2003-2013) climatological trends and variations in aerosol optical parameters retrieved from MODIS over three stations in South Africa. Atmospheric Environment, 95, 400-408.

Levy, R. C., Remer, L. A., \& Dubovik, O. (2007). Global aerosol optical properties and application to Moderate Resolution Imaging Spectroradiometer aerosol retrieval over land. Journal of Geophysical Research: Atmospheres, 112(D13).

Lippmann, M. (Ed.). (2000). Environmental toxicants: human exposures and their health effects. John Wiley \& Sons.

Liu, Z., Liu, D., Huang, J., Vaughan, M., Uno, I., Sugimoto, N., \& Winker, D. (2008). Airborne dust distributions over the Tibetan Plateau and surrounding areas derived from the first year of CALIPSO lidar observations. Atmospheric Chemistry and Physics, 8(16), 5045-5060.

Lodhi, N. K., Beegum, S. N., Singh, S., \& Kumar, K. (2013). Aerosol climatology at Delhi in the western Indo-Gangetic Plain: Microphysics, long-term trends, and source strengths. Journal of Geophysical Research: Atmospheres, 118(3), 1361-1375.

Lyamani, H., Olmo, F. J., \& Alados-Arboledas, L. (2008). Light scattering and absorption properties of aerosol particles in the urban environment of Granada, Spain. Atmospheric Environment, 42(11), 2630-2642.

Mao, K. B., Ma, Y., Xia, L., Chen, W. Y., Shen, X. Y., He, T. J., \& Xu, T. R. (2014). Global aerosol change in the last decade: An analysis based on MODIS data. Atmospheric Environment, 94, 680-686.

Mhawish, A., Banerjee, T., Broday, D. M., Misra, A., \& Tripathi, S. N. (2017). Evaluation of MODIS Collection 6 aerosol retrieval algorithms over Indo-Gangetic Plain: Implications of aerosols types and mass loading. Remote sensing of environment, 201, 297-313.

Mulenga, D., \& Siziya, S. (2019). Indoor air pollution related respiratory ill health, a sequel of biomass use. Sci Medicine Journal, 1(1), 30-37.

Myhre, G., Stordal, F., Johnsrud, M., Kaufman, Y. J., Rosenfeld, D., Storelvmo, T., \& Isaksen, I. S. A. (2006). Aerosolcloud interaction inferred from MODIS satellite data and global aerosol models. Atmospheric Chemistry and Physics Discussions, 6(5), 9351-9388.

Patel, P. N., \& Kumar, R. (2015). Estimation of aerosol characteristics and radiative forcing during dust events over Dehradun. Aerosol Air Quality Research, 15(5), 2082-2093.

Ranjan, R. R., Joshi, H. P., \& Iyer, K. N. (2007). Spectral variation of total column aerosol optical depth over Rajkot: A tropical semi-arid Indian station. Aerosol Air Quality Research, 7(1), 33-45.

Remer, L. A., Kaufman, Y. J., Tanré, D., Mattoo, S., Chu, D. A., Martins, J. V., \& Eck, T. F. (2005). The MODIS aerosol algorithm, products, and validation. Journal of the Atmospheric Sciences, 62(4), 947-973.

Rupakheti, D., Kang, S., Bilal, M., Gong, J., Xia, X., \& Cong, Z. (2019). Aerosol optical depth climatology over Central Asian countries based on Aqua-MODIS Collection 6.1 data: Aerosol variations and sources. Atmospheric Environment, 207, 205-214.

Sagar, R., Kumar, B., Dumka, U. C., Moorthy, K. K., \& Pant, P. (2004). Characteristics of aerosol spectral optical depths over Manora Peak: A high-altitude station in the central Himalayas. Journal of Geophysical Research: Atmospheres, 109(D6).

Savtchenko, A., Ouzounov, D., Ahmad, S., Acker, J., Leptoukh, G., Koziana, J., \& Nickless, D. (2004). Terra and Aqua MODIS products available from NASA GES DAAC. Advances in Space Research, 34(4), 710-714.

Schuster, G. L., Dubovik, O., \& Holben, B. N. (2006). Angstrom exponent and bimodal aerosol size distributions. Journal of Geophysical Research: Atmospheres, 111(D7).

Sharma, N. L., Kuniyal, J. C., Singh, M., Dhyani, P. P., Guleria, R. P., Thakur, H. K., \& Rawat, P. S. (2012). Atmospheric aerosol characteristics retrieved using ground based solar extinction studies at Mohal in the Kullu valley of northwestern Himalayan region, India. Journal of Earth System Science, 121(1), 221-235.

Solanki, R., Singh, N., Pant, P., Dumka, U. C., Kumar, Y. B., Srivastava, A. K., \& Chandola, H. C. (2013). Detection of long range transport of aerosols with elevated layers over high altitude station in the central Himalayas: A case study on 22 and 24 March 2012 at ARIES, Nainital. 92.60. Mt.

Solanki, R., \& Singh, N. (2014). LiDAR observations of the vertical distribution of aerosols in free troposphere: Comparison with CALIPSO level-2 data over the central Himalayas. Atmospheric Environment, 99, 227-238.

Srivastava, A. K., Bisht, D. S., Singh, S., Kishore, N., Soni, V. K., Singh, S., \& Tiwari, S. (2018). Scattering and absorption characteristics of aerosols at an urban megacity over IGB: Implications to radiative forcing. Atmospheric Research, 205, 107-117.

Srivastava, A. K., Singh, S., Tiwari, S., Kanawade, V. P., \& Bisht, D. S. (2012). Variation between near-surface and columnar aerosol characteristics during the winter and summer at Delhi in the Indo-Gangetic Basin. Journal of Atmospheric and Solar-Terrestrial Physics, 77, 57-66.

Stein, A. F., Draxler, R. R., Rolph, G. D., Stunder, B. J. B., Cohen, M. D., \& Ngan, F. (2015). NOAA's HYSPLIT atmospheric transport and dispersion modeling system. Bulletin of the American Meteorological Society, 96, 
2059-2077. https://doi.org/10.1175/BAMS-D-14-00110. 1[InlineImageRemoved]

Thanh, N. T. (2019). Evaluation of multi-precipitation products for multi-time scales and spatial distribution during 20072015. Civil Engineering Journal, 5(1), 255-267.

Tiwari, S., \& Singh, A. K. (2013). Variability of aerosol parameters derived from ground and satellite measurements over Varanasi located in the Indo-Gangetic Basin. Aerosol Air Quality Research, 13, 627-638.

Toledano, C., Cachorro, V. E., Berjon, A., De Frutos, A. M., Sorribas, M., De la Morena, B. A., \& Goloub, P. (2007). Aerosol optical depth and Ångström exponent climatology at El Arenosillo AERONET site (Huelva, Spain). Quarterly Journal of the Royal Meteorological Society: A journal of the atmospheric sciences, applied meteorology and physical oceanography, 133(624), 795-807.

Vanos, J. K., Cakmak, S., Kalkstein, L.S., Yagouti, A. (2015). Association of weather and air pollution interactions on daily mortality in 12 Canadian cities. Air Quality Atmosphere Health, 8(3), 307-320. https://doi.org/10.1007/ s11869-014-0266-7
Von Schneidemesser, E., Monks, P. S., Allan, J. D., Bruhwiler, L., Forster, P., Fowler, D., \& Sindelarova, K. (2015). Chemistry and the linkages between air quality and climate change. Chemical Reviews, 115(10), 3856-3897.

Yang, X., Zhao, C., Guo, J., \& Wang, Y. (2016). Intensification of aerosol pollution associated with its feedback with surface solar radiation and winds in Beijing. Journal of Geophysical Research: Atmospheres, 121(8), 4093-4099.

Yu, H., Dickinson, R. E., Chin, M., Kaufman, Y. J., Zhou, M., Zhou, L. \& Holben, B. N. (2004). Direct radiative effect of aerosols as determined from a combination of MODIS retrievals and GOCART simulations. Journal of Geophysical Research: Atmospheres, 109(D3).

Publisher's Note Springer Nature remains neutral with regard to jurisdictional claims in published maps and institutional affiliations. 